ISTORIJA MEDICINE / HISTORY OF MEDICINE ETIČKO PITANJE / ETHICAL ISSUE

\title{
ETIČKE DILEME U MEDICINSKOM TRETMANU NOVOROĐENČADI SA TEŠKIM KONGENITALNIM MALFORMACIJAMA: ZAOSTAVŠTINA BEBE DOE
}

\author{
Dejan Živanović ${ }^{1}$, Jovan Javorac ${ }^{1,2}$, Branislav Filipović́ ${ }^{3}$, Aleksandra Doronjski ${ }^{4,5}$, Ana Milenković2 \\ Zvonko Dimoski ${ }^{6}$, Mirjana Smuđa ${ }^{6}$ \\ 1. Katedra za biomedicinske nauke, Visoka škola strukovnih studija za obrazovanje vaspitača i trenera; Subotica, Srbija \\ 2. Klinika za granulomatozne i intersticijumske bolesti pluća, Institut za plućne bolesti Vojvodine; Sremska Kamenica, Srbija \\ 3. Katedra za pedagoške nauke, Visoka škola strukovnih studija za obrazovanje vaspitača i trenera; Subotica, Srbija \\ 4. Katedra za pedijatriju, Medicinski fakultet, Univerzitet u Novom Sadu; Novi Sad, Srbija \\ 5. Institut za zdravstvenu zaštitu dece i omladine Vojvodine; Novi Sad, Srbija \\ 6. Katedra za zdravstvenu negu, Visoka zdravstvena škola strukovnih studija, Akademija strukovnih studija; Beograd, Srbija
}

Autor za korespodenciju:

Ass. msr Dejan Živanović

email: dejanzivanovic@vsovsu.rs
Proces prihvatanja/Article history:

Primljen/Received 18.07.2021.

Prihvaćen/Accepted 12.09.2021.

\section{SAŽETAK}

Terapijski pristup u tretmanu novorođenčadi sa po život opasnim telesnim malformacijama je kroz istoriju bio predmet čestih i velikih moralnih dilema u struci i javnosti. „Slučaj bebe Doe“, svakako je najpoznatiji u novijoj istoriji medicinske prakse i prvi koji je dobio zvaničan sudski epilog, rezultirajući donošenjem niza zakonskih odredbi u vezi sa medicinskim tretmanom teško oštećene novorođenčadi. Bez obzira na razlike koje postoje u neonatološkoj praksi različitih država u svetu, etičke odluke zdravstvenih radnika u ovoj oblasti kliničke medicine treba da budu isključivo zasnovane na sveobuhvatnoj i objektivnoj proceni zdravstvenog stanja novorođenog deteta, razmatranju indikacija za primenu potencijalnih mogućnosti lečenja ili palijativne nege, i uvek vođene najboljim interesom novorođenčeta. Eutanazija u bilo kom obliku predstavlja nepotrebno, i za društvo i medicinsku praksu opasno rešenje, a umesto za njenu legalizaciju u neonatologiji, treba se zalagati za razvoj palijativne nege, kao humanistički nastrojenog pristupa u zbrinjavanju najtežih bolesnika.

Ključne reči: etičke dileme, novorođenče, kongenitalne malformacije, beba Doe

\begin{abstract}
Regardless of the differences in the neonatological practice of different countries in the world, ethical decisions of medical professionals in this field of clinical medicine should be based solely on a comprehensive The approach to the treatment of newborns with life-threatening body malformations has historically been the subject of numerous ethical dilemmas among the medical professionals and the general public. "The case of baby Doe" is certainly the most notable example in the recent medical history of the previously mentioned ethical dilemmas and was the first to result in an official juridical epilogue in a form of a series of legal provisions regarding the medical treatment of severely damaged newbornsand objective assessment of the health of the newborn, consideration of indications for potential treatment or palliative care, and always guided by the best interests of the newborn. Euthanasia in any form is an unnecessary solution, dangerous for society in general and medical practice, and instead of its legalization in neonatology, the development of palliative care, as a humanistic approach in the health care of the most challenging patients, should be emphasised.
\end{abstract}

Key words: ethical dilemmas, newborn, congenital malformations, baby Doe 


\section{UVOD}

Uprkos činjenici da je princip „Primum non nocere" suštinski važan za sve zdravstvene profesije i treba da predstavlja bazičnu smernicu u lečenju i nezi svih kategorija pacijenata, praksa pokazuje da su zdravstveni radnici često izloženi velikom broju etičkih dilema tokom obavljanja svakodnevnih profesionalnih aktivnosti [1]. Pitanja života i smrti, odnosno donošenje odluka čiji je krajnji ishod preživljavanje ili umiranje neke osobe, svakako spadaju u red večitih, najstresnijih i najtežih moralnih dilema sa kojima se susreću zdravstveni profesionalci, a etička delikatnost ovakvih situacija naročito dolazi do izražaja ukoliko se one odnose na vulnerabilne populacione kategorije, poput dece rođene sa različitim oblicima telesnih anomalija. Terapijski pristup u tretmanu novorođenčadi sa po život opasnim telesnim malformacijama je kroz istoriju bio predmet čestih i velikih moralnih dilema u struci i javnosti, sa stavovima koji su se kretali od mogućnosti primene pasivne eutanazije, pa sve do obaveze pružanja svih raspoloživih metoda lečenja i nege, predloženih ne samo od zdravstvenih radnika, već i od roditelja teško oštećene dece, koji su neizostavno morali biti uključeni u proces donošenja takvih odluka. Iako je sasvim verovatno da nije bio jedini ni do tada, a ni do današnjih dana, slučaj uskraćivanja lečenja novorođenčetu sa teškim urođenim anomalijama na osnovu odluke roditelja početkom ' 80 -ih godina prošlog veka u SAD, tzv. „Slučaj bebe Doe“, svakako je najpoznatiji u novijoj istoriji medicinske prakse i prvi koji je dobio zvaničan sudski epilog, pokrenuvši pravu lavinu etičkih pitanja i dilema koja su podelila ne samo laičku, već i stručnu javnost u celom svetu. I danas, gotovo 40 godina od pomenutog događaja koji je rezultirao donošenjem niza zakonskih odredbi u vezi sa medicinskim tretmanom teško oštećene novorođenčadi, pitanje ispravnosti, pravednosti i moralne zasnovanosti ovakvih odluka u svakom pojedinačnom slučaju je još uvek izuzetno aktuelno, prvenstveno zbog objektivnog prigovora javnosti da zdravstveni stručnjaci zaista ne mogu uvek i sa sigurnošću da predvide ishod preduzetih mera lečenja i kvalitet kasnijeg života novorođenčeta, zatim dileme u vezi sa tim da li i ko ima pravo da donosi odluke o prestanku života drugog ljudskog bića koje nije sposobno da izrazi sopstvene stavove i želje, ali i postojanja niza savremenih i naprednih medicinskih procedura i metoda koja mogu značajno produžiti život, odnosno odložiti smrt i najtežim bolesnicima.
Etički aspekti lečenja i nege novorođenčadi sa teškim kongenitalnim anomalijama: slučaj bebe Doe

Beba Doe (ime koje se u SAD uobičajeno koristi za novorođenče nepoznatog identiteta, kao i za zaštitu identiteta dece koja su na bilo koji način umešana u sudski proces) je rođena u aprilu 1982. godine u Indijani, SAD. Nakon rođenja, kod novorođenčeta je dijagnostikovan Daunov sindrom, traheoezofagealna fistula i atrezija jednjaka. Za razliku od porodičnog lekara i bolničkog pedijatra koji su smatrali da je operativno lečenje deteta izvodljivo i sa velikim šansama da bude uspešno, akušer koji je izveo porođaj, i sam otac deteta sa Daunovim sindromom, bio je mišljenja da zbog prisustva ove hromozomopatije novorođenče ne treba podvrgavati hirurškom lečenju fistule i atrezije, i tako je i savetovao roditelje deteta, navodeći da će dete najverovatnije biti teško teško mentalno retardirano, te da će urođene srčane mane zahtevati i višestruko hirurško lečenje novorođenčeta, sa malim šansama za preživljavanje. Roditelji su odlučili da poslušaju savet akušera i odbili hirurško lečenje deteta, a bolnica u kojoj je beba Doe rođena je zbog toga zatražila mišljenje lokalnog suda, u nameri da zaštiti sopstvene interese u slučaju eventualnog podnošenja tužbe. Bez jasnog medicinskog koncenzusa, sudija lokalnog suda je presudio u korist roditelja, navodeći da je njihova odluka u skladu sa najboljim interesima deteta. Pre nego je slučaj stigao da bude iznet pred državni vrhovni sud, beba Doe je umrla od dehidratacije i pneumonije, šest dana nakon rođenja $[2,3]$.

Nedugo nakon ovog događaja, 1983. godine, u SAD je rođena još jedna devojčica koja je u javnosti ubrzo dobila pseudonim beba Jane Doe. I ovo novorođenče je patilo od višestrukih urođenih anomalija: spine bifide, hidrocefalusa i mikrocefalusa. Bila je prvo i željeno dete mladog pobožnog bračnog para katoličke veroispovesti. Lekari su roditeljima savetovali hiruršku intervenciju u cilju zatvaranja defekta kičmenog stuba i obezbeđivanja drenaže likvora, sa napomenom da bi dete bez primene operativnog lečenja moglo da preživi oko dve godine, dok bi se njen životni vek operacijom mogao produžiti na oko 20-ak godina, ali sa visokim rizikom za nastanak brojnih zdravstvenih sekvela - roditeljima je skrenuta pažnja da će devojčica najverovatnije biti potpuno nepokretna, višestruko ometena u razvoju i imati česte epileptične napade, kao i perzistentnu infekciju urinarnog trakta. Takođe, lekari su saopštili roditeljima da smatraju da eventualna operacija 
svakako neće bitno uticati na budući kvalitet života novorođenčeta. Imajući to u vidu, a nakon brojnih konsultacija sa drugim lekarima, sveštenicima i socijalnim radnicima, roditelji su se odlučili za konzervativno lečenje deteta, ne dozvolivši operaciju. Za slučaj je saznao izvesni advokat i aktivista pokreta za pravo na život, podneo tužbu protiv roditelja i bolnice, ali je sud i u ovom slučaju doneo odluku u korist roditelja, smatrajući je razumnom u odnosu na zdravstveno stanje deteta. Međutim, kako je sudski proces potrajao četiri meseca, kod devojčice je došlo do spontanog zatvaranja otvora na kičmenom stubu, zbog čega su roditelji na kraju ipak dali dozvolu za ugradnju ventrikuloperitonealnog šanta. Godinama kasnije, novinari su izveštavali o napretku vesele devojčice Kerry Lynn koja se smeje, igra sa drugom decom, komunicira sa roditeljima i aktivno učestvuje u svakodnevnom životu svoje porodice. Dostigla je intelektualni nivo osmogodišnjeg deteta i pohađala školu za decu sa posebnim potrebama. Očigledno, kvalitet njenog života je bio daleko iznad prvobitnih prognoza, a s obzirom da je devojčica operisana tek nakon nekoliko meseci, postojala je i objektivna mogućnost da je kvalitet njenog života mogao biti čak i veći da je lečenje odmah preduzeto [4,5].

Za kratko vreme, slučajevi beba Doe su izazvali veliku pažnju medija i javnosti i doveli do brojnih etičkih rasprava. U prvom slučaju, nad novorođenčetom je izvedena pasivna eutanazija, dok je slučaj druge devojčice doveo u fokus činjenicu da su medicinske prognoze o mogućnostima oporavka i kvalitetu budućeg života očigledno bile pogrešne. Kao reakcija na ove događaje, Kongres SAD 1984. godine usvaja amandman na Zakon o prevenciji i tretmanu zlostavljanja u dečijem uzrastu, takozvani "Baby Doe zakon”, kojim su propisane smernice za medicinski tretman hendikepirane novorođenčadi, nezavisno od želje roditelja. Prema ovom zakonu, razlog uskraćivanja lečenja novorođenčadi sa kongenitalnim anomalijama može biti isključivo nemogućnost da ista obezbedi preživljavanje deteta, sa jasnom naznakom da se stavovi i razmatranja zdravstvenih radnika o budućem kvalitetu života ove dece ne mogu smatrati valjanim razlogom za uskraćivanje medicinske nege, u pravnom smislu [5]. "Baby Doe zakon" jasno definiše da pojam "uskraćivanja medicinski indikovanog lečenja” podrazumeva izostanak neophodnih aktivnosti zdravstvenih profesionalaca u pogledu pružanja lečenja i nege koje je primereno zdravstvenom stanju deteta, uključujući i odgovarajući način ishrane, hidratacije i primenu lekova, osim u sledećim slučajevima:

- kada se novorođenče hronično i ireverzibilno nalazi u stanju kome,

- kada bi pružanje takvog načina lečenja samo produžilo ili odložilo proces umiranja, odnosno ne bi efikasno uticalo na trajno otklanjanje ili ublažavanje po život opasnih sporemećaja zdravlja kod novorođenčeta, kao i na bilo koji drugi način bilo uzaludno u smislu preživljavanja deteta,

- kada bi pružanje takvog načina lečenja bilo ne samo uzaludan, već i nehuman čin prema novorođenčetu [3].

Novom zakonu su se snažno usprotivila strukovna udruženja lekara i pedijatara SAD, pa je čak i dr Everett Koop, tadašnji ministar zdravlja u vladi Ronalda Regana i pokretač inicijative za usvajanje pomenutog amandmana, priznao da postoje određena stanja u neonatologiji za koje i on smatra da bi neopravdano bila uvršćivana u kriterijume za održavanje života: anencefalična novorođenčad, novorođenčad sa teškim intrakranijalnim krvavljenjem i novorođenčad kojima nedostaje veći deo gastrointestinalnog trakta [6].

Najveću osudu javnosti je izazvala tužna sudbina prve bebe Doe, čiji je neposredni uzrok smrti u bolničkim uslovima na kraju 20. veka bio dehidratacija. Iako nije zakonom zabranjena u većini zemalja sveta, pasivna eutanazija, odnosno nepreduzimanje neophodnih mera za produženje života nikako ne bi smela biti "metoda izbora" u medicinskom tretmanu novorođenčadi koja su rođena sa teškim anomalijama. Jasno je da u slučaju urođenih malformacija novorođenčadi postoji jasan moralni sukob između neprikosnovenosti ljudskog života kao najviše vrednosti i empatijski zasnovane želje da se pomogne drugom biću i umanji njegov bol i patnja. Međutim, većina stručnjaka se slaže u stavu da eutanazija u bilo kom obliku predstavlja nepotrebno, i za društvo i medicinsku praksu opasno rešenje, a umesto za njenu legalizaciju u neonatologiji, treba se zalagati za razvoj palijativne nege, kao humanistički orijentisanog pristupa u tretmanu novorođenčadi sa teškim i po život opasnim anomalijama $[7,8]$. Takođe, oba slučaja su izazvala žustre polemike o tome da li roditelji, zdravstveni radnici, ili bilo koja treća osoba može doneti odluku o prestanku života drugog ljudskog bića. Čak i eutanazija kao pojam determiniše samosvesnu, autonomnu i racionalnu odluku individue o prestanku 
sopstvenog života, a jasno je da novorođenče, bilo zdravo ili ne, nema mentalnih potencijala za donošenje bilo kakvih, pa samim tim ni odluka o vlastitom životu. Dakle, novorođena deca su bespomoćna osećajuća bića koja nisu ni samosvesna, ni racionalna, što ih čini jednom od najvulnerabilnijih populacionih kategorija, ali činjenica da pripadaju ljudskom rodu obavezuje sve samosvesne i racionalne osobe da im omoguće uživanje svih onih prava koje druge ljudske jedinke imaju, a pre svega - pravo na dostojanstven život, sve dok je to moguće. Kako u slučaju novorođenčadi ne može biti razmatran aspekt autonomije u sopstvenim odlukama, pojedini autori smatraju da kvalitet budućeg života ipak treba da bude važan činilac odluka o medicinskom tretmanu neonatusa sa kongenitalnim anomalijama, bez obzira na objektivnu mogućnost pogrešnih procena, kao u slučaju bebe Jane Doe [9]. Medicinska etika nalaže da, i pored specifičnosti svake pojedinačne situacije, svi zdravstveni radnici koji rade u službama za neonatologiju treba da se pridržavaju sledećih moralnih načela:

- svako ljudsko biće je jedinstveno i ima pravo da živi sopstveni život,

- svako ljudsko biće ima svoj sopstveni integritet koji ne sme biti narušen,

- svako ljudsko biće ima pravo na optimalno lečenje i zdravstvenu negum

- svako ljudsko biće ima pravo da bude deo društva i uživa dobra koje društvo nudi,

- srž svih procena i odluka koje se donose u vezi sa lečenjem treba da bude najbolji interes novorođenčeta,

- na odluke zdravstvenih radnika ne smeju da utiču lični ili društveni stavovi u vezi sa vrednošću života,

- retardacija ili onesposobljenost sami po sebi nisu razlog za izostanak primene ili obustavljanje lečenja,

- izostanak primene ili prekidanje primene resuscitacionih mera su ekvivalentni u etičkom smislu,

- odluke o nepreduzimanju ili prekidanju lečenja treba uvek da budu dovršene odlukom o započinjanju mera palijativnog zbrinjavanja,

- roditelji treba da budu uključeni u sve odluke koje se tiču lečenja deteta, ali njihova odluka ne sme biti presudna ukoliko lekar smatara da postoje objektivne mogućnosti za efikasno lečenje,
- u slučaju razmimoilađenja stavova između članova medicinskog tima ili članova tima i roditelja, uvek treba insistirati na drugom ekspertskom mišljenju,

- svaki vid namernog ubijanja vitalno ugrođenog novorođenčeta je u etičkom i pravnom smislu nedopustiv; sa druge strane, primena lekova koji će olakšati trpljenje, ali istovremeno mogu kao neželjeno dejstvo prouzrokovati smrtni ishod, može biti opravdana ukoliko su za primenu leka postojale objektivne indikacije,

- sa odlukama u vezi sa započinjanjem ili obustavljanjem nedicinskog tretmana nikada ne treba žuriti, već treba da budu zasnovane na objektivnim činjenicama i da reprezentuju zajednički stav svih članova medicinskog tima [10].

I danas, dugi niz godina nakon što su se dogodili slučajevi beba Doe, u svetu postoje značajne razlike u stavovima neonatologa i kliničara u pogledu tretmana teško fizički i/ili mentalno oštećene novorođenčadi, ali i uključivanja roditelja i trećih lica u donošenje ovih odluka [11]. U poslednje dve decenije, tehnološki razvoj u oblasti medicine i značajno povećanje različitih konzervativnih i hirurških metoda za lečenje i resuscitacionu podršku su značajno povećali stopu preživljavanja vitalno ugrožene novorođenčadi. I pored toga, izgledi za preživljavanje neonatusa su i dalje minimalni ukoliko se radi o teškim malformacijama ili novorođenčadi sa ekstremno malom porođajnom masom [8]. Prema podacima Američkog koledža za akušerstvo i ginekologiju (American College of Obstetricians and Gynecologists), preživljavanje neonatusa rođenih pre 21. gestacijske nedelje nije zabeleženo, kod onih koji su rođeni pre 24. gestacijske nedelje stopa preživljavanja je veoma niska i praćena ozbiljnim neurološkim oštećenjima, dok je preživljavanje novorođenčadi rođenih u 25. gestacijskoj nedelji čak 75\%. I u ovom slučaju, glavna etička dilema se odnosi na to ko treba da donese odluku o primeni mera reanimacije i lečenju na osnovu principa dobre kliničke prakse ukoliko novorođenče preživi ili, umesto toga, samo primeni mera palijativnog lečenja. U zemljama u kojima postoje zvanične preporuke u pogledu primene mera reanimacije $u$ neonatologiji, odluka je prilično jednostavna i u većini slučajeva vođena postojećim smernicama. Međutim, u zdravstvenim sistemima u kojima vodiči dobre kliničke prakse iz te oblasti i zakonske uredbe gotovo i ne postoje (kao što je to slučaj i sa Srbijom), donošenje odluke koja se odnosi na život, odnosno 
smrt novorođenčeta i te kako može biti teška, dramatična i praćena brojnim moralnim dilemama [12]. Proistekla upravo iz takvih i sličnih situacija, nameću se različita etička pitanja koja su i danas, četiri decenije nakon slučajeva beba Doe, izuzetno aktuelna u stručnim krugovima:

- da li treba primeniti mere lečenja kod svakog novorođenčeta, uprkos objektivnom stanju (gestaciona starost, prisustvo anomalija ili drugih zdravstvenih poremećaja)?

- da li roditelji treba da imaju pravo odlučivanja za sudbinu novorođenčeta?

- kada je medicinski tretman već započet, da li ga treba nastavljati i pored naznaka da će novorođenče kasnije biti višestruko hendikepirano, ukoliko preživi?

- u kojim slučajevima treća lica, izuzev roditelja, imaju pravo da donesu odluku o započinjanju ili okončanju primene mera lečenja, i da li u tom slučaju ona mogu biti odgovorna za troškove nege i lečenja teško hendikepiranog deteta? [10].

$\mathrm{Na}$ osnovu principa o očuvanju i zaštiti intergiteta ljudskog tela, svaka svesna osoba ima legitimno pravo da prihvati ili odbije predložene mere lečenja. Suštinska etička dilema u neonatologiji je na koji način primeniti ovaj princip kod novorođenčadi koja nemaju sposobnost da traže primenu ili zahtevaju obustavu lečenja - da li medicinski tretman treba svakako primeniti jer njihova volja ne može biti poznata, ili roditelji i staratelji mogu samostalno doneti odluku da primena lečenja nije u najboljem intereseu novorođenog deteta. Roditelji imaju obavezu da brinu o interesima svog deteta, ali je etičko i pravno pitanje da li se u tu brigu može svrstati i pravo da donose odluke koje mogu direktno uticati na okon- čanje detetovog života. Sa druge strane, i zdravstveni radnici imaju obavezu da spreče, zaustave ili umanje patnju pacijenata u meri u kojoj je to moguće. Ako je osnovna smernica u radu zdravstvenih profesionalaca da održe pacijenta u životu, istovremeno se nameće i pitanje da li je život vrednost sam po sebi, ili budući kvalitet života treba da ima presuđujuću ulogu u etičkim odlukama osoblja neonatoloških ustanova, i pored primera da to ponekad može da bude osnov sasvim pogrešnih profesionalnih procena.

\section{ZAKLJUČAK}

Imajući u vidu složenost i sve navedene etičke elemente donošenja odluka $u$ vezi sa lečenjem novorođene dece sa teškim malformacijama ili drugim stanjima koja su neposredni uzrok njihove vitalne ugroženosti, kao i ograničene mogućnosti bilo koje zakonske regulative da obuhvati sve potencijalne situacije u kojima je nužno doneti moralno ispravnu odluku, nameće se logičan zaključak da one i ne treba da budu regulisane rigidnim zakonskim odredbama, niti vođene rigidnom željom roditelja ili strahom zdravstvenog radnika od potencijalne krivične odgovornosti i kazne. Bez obzira na razlike koje postoje u neonatološkoj praksi različitih država u svetu, etičke odluke zdravstvenih radnika u ovoj oblasti kliničke medicine treba da budu isključivo zasnovane na sveobuhvatnoj i objektivnoj proceni zdravstvenog stanja novorođenog deteta, razmatranju indikacija za primenu potencijalnih mogućnosti lečenja ili palijativne nege, i uvek vođene najboljim interesom novorođenčeta. Ujedno, to je i najbolji i najefikasniji način da se iskoristi moralna zaostavština dece kojima je bilo uskraćeno pravo na lečenje i život, i spreči pojava novih slučajeva beba Doe u zdravstvenim sistemima širom sveta. 


\section{LITERATURA}

1. Marić J. Medicinska etika. Beograd: Megraf; 2001.

2. Lang GC. "Baby Doe" - a medical ethical issue. West J Med. 1985;142(6):837-41.

3. White M. The end at the beginning. The Ochsner Journal. 2011;11(4):309-16.

4. Annas GJ. The case of baby Jane Doe: child abuse or unlawful federal intervention? Am J Public Health. 1984;74(7):727-9.

5. Singer P. Sanctity of life or quality of life. Pediatrics. 1983;72(1):128-9.

6. Stevenson DK, Ariagno RL, Kutner JS, Raffin TA, Young EW. The "Baby Doe" rule. JAMA. 1986; 255(14):1909-12.

7. Frković A, Wickerhauser Majer T. Bioetička razmatranja o palijativnoj skrbi u novorođenačkoj dobi. Paediatrija Croatica. 2006;50(1):17-21.

8. Duraković D. Eutanazija u dječjoj dobi. JAHR. 2014;5/2(10):387-405.

9. Singer P. Praktična etika (prevod na hrvatski jezik). Zagreb: KruZak; 2003.

10. Sauer PJJ et al. Ethical dilemmas in neonatology: recommendations of the Ethics Working Group of the CESP (Confederation of European Specialists in Paediatric). Eur J Pediatr. 2001;160:364-68.

11. Placencia FX, Ahmadi Y, McCullough LB. Three decades after baby Doe: how neonatologists and bioethicists conceptualize the Best Interests Standard. Journal of Perinatology. 2016; 1-6.

12. Doronjski A, Stojanović V. Ethical issues in the treatment of extremely low birth weight neonates. Croat Med J. 2016;57(4):395-7. 